\title{
Influence of the temperature and pressure on densification, physical and mechanical properties of Inconel 718 produced by Hot Pressing
}

Ana Cristina Marques ( $\sim$ anacristinamarques95@gmail.com )

Universidade do Minho Centro de Sistemas Microeletromecânicos https://orcid.org/0000-0001-54183453

Ângela Cunha

Filipe Silva

Flávio Bartolomeu

Oscar Carvalho

\section{Research Article}

Keywords: Inconel 718, Hot Pressing, Densification, Grain size, Fracture mode, Hardness

Posted Date: February 22nd, 2022

DOI: https://doi.org/10.21203/rs.3.rs-1347468/v1

License: (c) (i) This work is licensed under a Creative Commons Attribution 4.0 International License.

Read Full License 


\section{Abstract}

This work aims to study the influence of hot-pressing (HP) sintering conditions (temperature and pressure) on Inconel 718 (Inc718) powders densification, microstructural, fracture mode and hardness properties. The sintering conditions included temperatures of 1000,1068 and $1150{ }^{\circ} \mathrm{C}$ and pressures of 50 and $60 \mathrm{MPa}$ for a dwell time of $60 \mathrm{~min}$. Fracture mode and the grain morphology were assessed by scanning electron microscopy (SEM). The grain size (GS) of the compacts increased with increasing HPed temperature and the fracture mode changed from intergranular dominant fracture to fully dimple ductile fracture. The microstructure features were characterized by X-ray diffraction (XRD) analysis. The results showed that intermetallic precipitate originated from the Inconel 718 powders were retained in the sintered specimens considered. The chromium Carbides ( ) were formed at $1068^{\circ} \mathrm{C}$ but were eliminated when HPed at and above $1150^{\circ} \mathrm{C}$ and $60 \mathrm{MPa}$ once they tend to dissolve when increasing temperature. The hardness results revealed that the sintering Inconel 718 powders at $1000{ }^{\circ} \mathrm{C}$ is not enough to promote the proper densification and so the optimum hardness results. For higher temperature (1068 and $1150^{\circ} \mathrm{C}$ ) the hardness results decrease from 292 to $283 \mathrm{HV}$ with increasing HP temperature (for $60 \mathrm{MPa}$ ) due to the dissolution of chromium carbides (). The pressure conditions also influenced powder's sintering but did not reveal a pronounced difference in densification and hardness results. Further investigations must consider a wide range of pressure values as well a deeply study on the microstructure features on particle grain boundaries.

\section{Introduction}

Inconel 718 is a superalloy widely used in aerospace engines because of its high mechanical properties, temperature resistance and corrosion resistance [1-3]. This nickel-based alloy is a $\gamma^{\prime \prime}$ precipitationhardenable nickel-chromium alloy with amounts of iron, niobium and molybenium [3]. This alloy is suitable to be processed by powder metallurgy techniques due to the substantial precipitation of strengthening elements that be can be added through atomization processes with no significant segregation [1]. Powder metallurgy (PM) manufacturing techniques consist in producing metal components by heating compacted metal powders below their melting points [4].The process involves three main processing steps: the production of the metal powder, followed by the compaction of the powder and the consolation of the powder into a component under high temperature and pressure [5]. These techniques avoid the use of post-processing techniques such as machining processes - which severely reduce the yield strength - and also reduce the costs.

The PM manufacturing techniques usually reported are Metal Injection Molding (MIM), Rolling, Extrusion, Hot Isostatic Pressing and Hot Pressing [5]. Metal injection molding (MIM) consists in the injection of metal powder mixed with the binder of polymers. Posteriorly, the binder is removed and the part is sintered. Davies et al [3] reported that this process seems to be promising in terms of mechanical properties, with close values to cast and wrought Inc718 parts (with Ultimate Tensile Strength of 1211 $\mathrm{MPa}$ by MIM, 1090 by Cast and $14350 \mathrm{MPa}$ by wrought) and fine-grained microstructure. However, the 
author concluded that there is a need a full-scale investigation to validate the material properties results [3].

Hot Isostatic Pressing (HIP) that combines pressure and temperature to produce densified parts directly from powders, with better mechanical properties when compared with other processes [6, 7]. Although HIP process allows to fabricate parts with complex geometries, high material use ratio and promote the microstructure homogeneity [8]. Chang et al [6] studied the effects of the temperature of the hot isostatic pressing (HIP) procedure on Inconel 718 superalloy. HIP temperatures used were 1150, 1175, 1180 and $1205^{\circ} \mathrm{C}$ and pressure was kept at $1000 \mathrm{MPa}(98.6 \mathrm{MPa})$ and the dwell time was $2 \mathrm{~h}$. They concluded that the microstructure and mechanical properties were improved by HIP process and at $1750 \mathrm{MPa}$ the porosity reduced $78.5 \%$ and decrease of the $\delta$ precipitation. Moreover, the tensile strength increased $18.48 \%$ at room temperature, $13.02 \%$ at $540^{\circ} \mathrm{C}$ and $20.11 \%$ at $650^{\circ} \mathrm{C}$ in tensile tests. Chang et al [9] reported unanticipated low mechanical properties due to the precipitation of undesirable phases such as carbides and oxides, alongside the PPBs. It was also reported changes on tensile fracture mode with the increase of temperature - from inert-particle dominant fracture to entirely dimple ductile fracture - due to the dissociating of the prior particle boundaries with the carbide particles.

Similarly, Hot Pressing (HP) is a manufacturing technique by which highly densified parts are produced through heating and pressing of metal or ceramic powders. Initially, the mechanical interlocking between the powders is promoted by the contact between their surface ridges and irregularities. The link/cohesion between these powders is enhanced by the increase of the area of contact between surface powders. The axial pressure applied enhanced the area of contact and modify the powder shape, that leads to an increase of the part strength. HP has been shown an effective sintering technique that allows to produce specimens with densification near by the theoretical values and mechanical properties close to the solid materials. This process is commonly used as post processing method sintered parts, consolidation of powders to near-net shapes and to diffuse and bond different materials [6]. The high temperature resistant materials, such as Inconel 718 alloy, are naturally harder to sinter than the remaining materials. The surface energy of small powders promote a driving force that combined with external pressure leads to faster densification [10]. The plastic deformation occurs when the material is at elevated temperatures and low stresses leading to an efficient deformation and so, densifying phenomenon.

The lack of information on the sintering mechanisms of the Inconel 718 powders by Hot Pressing technology as well the resulting consolidation, microstructure features and mechanical properties makes this paper a potential tool for future investigations on this field. In this sense, the aim of the present work was to investigate the influence of the hot-pressing temperature and pressure conditions on the final densification, microstructural and mechanical properties.

\section{Methods}

\subsection{Powder characterization}


In the optimization of Inconel 718 hot pressing sintering conditions was used Inconel 718 powder, from Carpenter Additive supplier, with 15-45 $\mu \mathrm{m}$ particle mean size. The morphology of the Inconel 718 powders was inspected by scanning electron microscopy (SEM) in agglomerate form (Fig. 1a) and presents the grain size distribution of Inconel 718 powders, confirming the range given by the manufacturers. Furthermore, it is possible to verify the presence of satellites on powder. The majority of the grain size powders measurements range between 20 and $35 \mu \mathrm{m}$ (Fig. 1b).

The chemical composition of Inconel alloy is described in Table 1. The nickel-based alloy containing up to $50-55 \%$ of $\mathrm{Ni}$ and $21 \%$ of $\mathrm{Cr}$ which promotes resistance to oxidation temperature differences. The presence of molybdenum (2.8-3.3\%) element gives resistance to pitting corrosion in the various conditions [11].

Table 1 - Chemical composition of Inconel 718 powder (Carpenter Additive Lda) [12].

\begin{tabular}{|llllllllllll|}
\hline & Al & Cr & Co & Cu & Fe & Mn & Mo & Ni & Nb+Ta & Si & Ti \\
\hline$w t \%$ & 0.70 & 21 & 1 & 0.3 & Balance & 0.35 & $2.8-3.3$ & $50-55$ & $4.75-5.50$ & 0.15 & 1.15 \\
\hline
\end{tabular}

Chromium (21\%) is responsible for resistance to high temperature oxidation and attack by hot sulfuric gases. The stiffening effect of molybdenum (2.8-3.3\%) element gives resistance to pitting corrosion in the various conditions [11]. Moreover, molybdenum and niobium on nickel-chromium matrix improves mechanical strength. Inconel alloys are constituted by several other elements such as aluminium, iron, cobalt, titanium. The high solubility of cobalt, iron, chromium, molybdenum and tungsten improves the strength of austenitic matrix $(\gamma)$ [13]. The XRD pattern (Fig. 2) of the Inconel 718 powder shows the solid solution of austenite $(\gamma)$ face-centered cubic $(\mathrm{fcc}) \mathrm{Ni}-\mathrm{Cr}$ matrix with dominant presence of $\gamma(111)$ plane.

\subsection{Hot Pressing}

Inconel 718 specimens were produced by Hot Pressing (HP) by using a vacuum pressure-assisted sintering system $\left(10^{-2} \mathrm{mbar}\right)$ with a high frequency induction furnace. The preliminary stage of the HP experimental procedure process included the weight of the powder and the painting of the graphite die surface with $\mathrm{ZrO}_{2}$ to prevent an undetectable carbon diffusion to specimen. Then, the powder is inserted into the graphite die and is placed into chamber of the system to be assembled in the hot-pressing structure with a thermocouple fitted into the graphite die to control the temperature near by the specimen (Fig. 3). The powder isheated at a rate of $5^{\circ} \mathrm{C} / \mathrm{s}$ and when $80 \%$ of the final temperature was achieved, the axial pressure was applied. Then, when the final temperature is achieved, the stage starts and both temperature and pressure were maintained during dwell time (60 min). Then, the specimens were cooled till the room temperature, removed from the graphite die and cylindrical specimens with $14 \mathrm{~mm}$ in diameter were obtained.

The simultaneous heating and pressing of the Inconel 718 powders allowed to enhance the bonding diffusion of the particles under high temperatures conditions. The bonding diffusion and the forming mechanical pressure enhanced the specimen's densification. The influence of these processing 
parameters on the matrix material's final properties were studied, being tested different conditions as shown in Table 2. As it was not found in literature the optimum sintering temperature values of Inconel 718 at hot pressing technology, it was chosen by considering $80 \%$ of the melting point of Inconel 718 $\left(1260-1336^{\circ} \mathrm{C}\right)[14]$. The pressure values considered in hot isostatic pressing were higher pressure values (98.6 -197.2 MPa) [6] than the those values used in this study (50 and $60 \mathrm{MPa}$ ). However, it is possible to compensate pressure with temperature (allowing to sinter at lower pressure) so higher temperature value than $80 \%$ of melting point were also evaluated $\left(1150^{\circ} \mathrm{C}\right)$.

Table 2

- Description of the Hot-Pressing Sintering conditions.

\begin{tabular}{|lll|}
\hline Designation & Temperature $\left.^{\circ}{ }^{\circ} \mathrm{C}\right)$ & Pressure (MPa) \\
\hline T1000P50 & 1000 & 50 \\
\cline { 1 - 1 } T1000P60 & & 60 \\
\cline { 1 - 1 } T1068P50 & 1068 & 50 \\
\cline { 1 - 1 } T1068P60 & & 60 \\
\cline { 1 - 1 } T1150P50 & 1150 & 50 \\
\cline { 1 - 1 } T1150P60 & & 60 \\
\hline
\end{tabular}

\subsection{Characterization techniques}

The powders' morphology of the obtained specimens was characterized through an ultra-high-resolution field-emission Scanning Electron Microscope (SEM). An integrated microanalysis system (EDS - energy dispersive spectrometer) allowed the analysis of the chemical composition of the specimens. The SEM analysis of the fracture surface were performed.

In the Inconel 718 metal alloys, the phase identification was executed by means of X-ray diffraction (XRD) analysis using a Bruker D8 Discover diffractometer. A classical $\theta-2 \theta$ analysis with a BraggBrentano geometry using CuKa radiation. The $2 \theta$ was measured with a stepsize of $0.04^{\circ}$ and a steptime of $4 \mathrm{~s} /$ step, ranging $30^{\circ}$ to $100^{\circ}$.

The grain morphology was assessed by etching the Inconel 718 specimen with a solution of Kallings No $2\left(10 \mathrm{ml}\right.$ ethanol, $10 \mathrm{HCl}(37 \%), 10 \mathrm{ml} \mathrm{H}_{2} \mathrm{O}$ and $0.5 \mathrm{~g} \mathrm{CuCl}_{2}$ ) for $3 \mathrm{~min}$ to be further evaluated by SEM.

The physical characterization of the produced specimens includes the estimation of the density by the conventional formula $\left(\rho=\mathrm{m} / \mathrm{V}\left[\mathrm{g} / \mathrm{cm}^{3}\right]\right)$. The mechanical characterization included microhardness tests using an EMCO-TEST (DuraScan model), considering a load of $100 \mathrm{~g}$ for $15 \mathrm{~s}$.

\section{Results}

\subsection{Densification and Physical properties}


Densification is affected by temperature (which enhance the atomic diffusion) and pressure (responsible for the plastic deformation) conditions [15]. When these two phenomena occurred, the polycrystalline aggregates of the powders are deformed, occurring static recrystallization and grain growth.

In order to analyses the densification of the Inconel 718 specimens, the density was calculated by using the conventional equation $(\rho=\mathrm{m} / \mathrm{V})$. The weight and volume of each specimen were measured values and the respective calculated density and densification are presented at Table 3.. The Inconel 718 theoretical density reported in literature is $8.20 \mathrm{~g} / \mathrm{cm}^{3}$ [16] so, it is possible to conclude that the density results of the produced specimens were close to the desired values (94.59-99.77\% of ensification).

Table 3

Calculated density and densification of the Inconel 718 specimens produced by Hot Pressing.

\begin{tabular}{|lll|}
\hline Designation & Calculated density $\left(\mathbf{g} / \mathrm{cm}^{3}\right)$ & Densification (\%) \\
\hline T1000P50 & 7.756 & 94.59 \\
\hline T1000P60 & 7.998 & 97.54 \\
\hline T1068P50 & 7.917 & 96.55 \\
\hline T1068P60 & 7.826 & 95.44 \\
\hline T1150P50 & 8.036 & 98.00 \\
\hline T1150P60 & 8.181 & 99.77 \\
\hline Theoretical values & $8.200[16]$ & 100 \\
\hline
\end{tabular}

Regarding the specimens produced by applying a pressure of $50 \mathrm{MPa}$, there was verified a decrease in the porosity with increasing temperature $\left(5.41 \%\right.$ for $1000^{\circ} \mathrm{C}, 3.45 \%$ for $1068{ }^{\circ} \mathrm{C}$ and $2.00 \%$ for $1150{ }^{\circ} \mathrm{C}$ ). These results allowedus to conclude that the sintering temperature has influence on the specimen's densification. On the other hand, it has been verified a very light increase on the densification with the pressure sintering (except for $1068^{\circ} \mathrm{C}$ ), so it is not enough to conclude about its influence on the densification.

The analysis of the grain morphology is extremely relevant once it allows to assess with specimen's densification and mechanical behavior. In this sense, the influence of temperature and pressure on the grain features can be observed at Fig. 4. The grain behavior during the solidification is based on two main stages: the nucleation, in which stable nuclei are formed, and the growth of nuclei that give rise to crystals and form a grain structure. At lower sintering temperature $\left(1000^{\circ} \mathrm{C}\right)$, small grains are dispersed and mixed with large grains, indicating that they only nucleated (but did not have the necessary temperature and time to grow). The atomic diffusion is usually driven by high temperatures resulting in a reduction in grain surface area and local curvature of free surface. Grains poorly bonded specific contact points (necks) were observed and was originated by a decrease of free energy surface. The low free energy surface inhibits the powder particles interaction by atomic diffusion mechanisms, creating voids. 
At $1068^{\circ} \mathrm{C}$, the grains presented a bi-modal random structure, with intermixed small and large grains which the majority of grown grains but the total recrystallization is still not complete. The surface contact stress between the powder particles is gradually reduced and the metal powder begins to recover and recrystallize. The intimately contacted powders stick to each other and the abovementioned voids are filled. Inconel 718 specimens produced at $1150^{\circ} \mathrm{C}$ revealed a greater grain size homogeneity there was not found grains that just nucleated.

Figure 4 showed the grain size of Inconel 718 specimens processed at different temperatures $(1000,1068$ and $1150^{\circ} \mathrm{C}$ ), considering sintering pressures of P50 and P60. In order to evaluate the influence of the temperature on grain growth, the grain measurements only considered the representative part of each of the specimens. Thus, for example, for the sample sintered at $1000^{\circ} \mathrm{C}$, the grains that grew little were not considered, since they are not representative of what is verified. The global analysis allowed to conclude that the grain size increase with the sintering temperature because it leads to increase the crystallinity of the material and hence increases the number of crystallites.

The diffraction patterns of Inconel 718 powder and specimens produced by hot pressing is shown in Fig. 5. The spectrum is coincident with solid solution of austenite $(\gamma)$ which is a single phased structure made of the main structure elements $(\mathrm{Ni}, \mathrm{Cr}, \mathrm{Fe})$. The main strain strengthening mechanisms of Inconel 718 are the $y \rrbracket$ phase and order strengthening from the $\gamma^{\prime}$ phase as well grain boundary strengthening [17]. The absence of this strengthening phase in these works is due to all HIPed specimens have been sintered above the solvus of the $y \rrbracket$ phase $\left(915^{\circ} \mathrm{C}\right)$ [18]. However, all the XRD spectrums revealed the stable strengthening $\gamma^{\prime} \mathrm{Ni}_{3}(\mathrm{Al}, \mathrm{Ti})$ that came from the Inconel 718 powder, which is also important improve strengthening of Inconel 718 parts whose usually require high strength and good corrosion resistance in wide temperature range. The rapid precipitation of $\gamma^{\prime} \mathrm{Ni}_{3}(A l, T i)$ phase is relevant for improving the strength but the low growth rate, when compared with $\gamma^{\prime \prime}\left(\mathrm{Ni}_{3} \mathrm{Nb}\right)$, makes it a secondary strengthening phase.

By increasing the sintering temperature, some elements such as $\mathrm{Cr}$ precipitated and formed chromium carbides such as $\mathrm{Cr}_{23} C_{6}$. Chromium carbides $\left(\mathrm{Cr}_{23} C_{6}\right)$ were coincident with $\gamma$ at $44^{\circ}$ for sintering temperatures between 1068 and $1150^{\circ} \mathrm{C}$. The amount of $\mathrm{Cr}_{23} C_{6}$ tend to decrease with the increase of temperature once this phase due its dissolution into the matrix [19].

Niobium $(\mathrm{Nb})$ is an element of Inconel 718 alloy which is highly predisposed to segregation, and consequently form precipitates. The low solidification rate an high temperature during Hot Pressing is probably to enhance macrosegregation of the $\mathrm{Nb}$, leading to the formation of undesirable phases $(\mathrm{Nb}, \mathrm{Ti}) \mathrm{C}$ for improving tensile ductility, fatigue and creep rapture properties. On the other hand, these Niobium Carbides are known as beneficial for improving hardness. XRD spectrums revealed different types of Niobium carbides such as $\mathrm{Nb}_{4} C_{3}$ and $(\mathrm{Nb}, \mathrm{Ti}) \mathrm{C}$, at 35 and $40^{\circ}$ in spectra for sintering conditions from 1000 to $1150{ }^{\circ} \mathrm{C}$. Niobium carbides were not revealed in XRD Inconel 718 powder 
spectrum because they were formed during solidification. This phase is considered a stable phase because its melting point is much higher $\left(3600^{\circ} \mathrm{C}\right)$ compared with Inconel 718 alloy $\left(1336^{\circ} \mathrm{C}\right)$.

\subsection{Mechanical properties}

The SEM images of the fracture surfaces (Fig. 6) allow analyzing the fracture mode and effectiveness of sintering conditions. These images showed a ductile fracture mode once it is possible to observe an extensive plastic deformation. The ductile fracture includes two distinct modes: intergranular and intragranular. Some specimens seem to have one single fracture mode and the remaining specimens a mix between different ductile fracture modes (intragranular mode with a marked shift towards intergranularity).

As already concluded, it was not verified an effective densification likely due to insufficient presence of the liquid phase. The fracture analysis of the T1000P50 specimen showed a completely split up of the powders which probably lead to the observed pure intergranular fracture mode. As the grains were poorly bonded, the crack propagation tended to be along the grain boundaries. However, the increase of pressure from 50 to $60 \mathrm{MPa}$ seemed to strongly contribute for improving the compaction of the powders once the contact area between powders was increased and so the local plasticity was enhanced. In this sense, fracture mode of T1000P60 specimens seems to be intragranular despite having some marks of intergranular mode.

The increasing of temperature to $1068^{\circ} \mathrm{C}$ revealed a strong influence on the powder's consolidation, resulting in a better metallurgical bonding when compared with the specimens sintered at $1000{ }^{\circ} \mathrm{C}$. The fracture surface of both T1068P50 and T068P60 specimens showed intragranular fracture mode with particle-boundary decohesion along dimples. These dimples may result from an increase on atomic diffusion and extensive plastic deformation. When increasing pressure from 50 to $60 \mathrm{MPa}$, the local plasticity is more evident at the fracture surface. The microvoids found on the T1068P60 fracture's surface can have been originated by pure mechanical loads or a from oxidation of grain boundary precipitates.

For the higher sintering temperature $\left(1150^{\circ} \mathrm{C}\right)$, there was verified a ductile intragranular fracture mode for both sintering pressures, with a good metallurgical bonding and powders consolidation. The specimens showed an almost completely dimple fracture which could be attributed to high atomic diffusion and plastic deformation [20].

Figure 7 presents the hardness results of Inconel 718 specimens grouped by temperatures of 1000, 1068 and $1150^{\circ} \mathrm{C}$ in order to assess the hardness evolution with increase of sintering temperature.

When considering a temperature of $1000^{\circ} \mathrm{C}$, the hardness results obtained were considerably lower than the remaining conditions $(241.35 \pm 33.93$ and $219.98 \pm 13.85 \mathrm{HV})$. Although the XRD spectrum have shown the presence of hardening phases such carbides $\left(\mathrm{NbC}\right.$ and $\left.\mathrm{Nb}_{4} \mathrm{C}\right)$, the poorly bonded powders (Fig. 6) are responsible for the global low hardness values. Although the smaller GS induces high 
hardness results due to the high amount of dislocations, the lack of powders consolidation was harmful to the hardness results. The specimens produced at $1068^{\circ} \mathrm{C}$ and $1150^{\circ} \mathrm{C}$ sintering temperatures revealed similar hardness results. The increase of temperature is not only essential for a strong metallurgical bonding (once enhance the atomic diffusion between the grains) but it can also promote the precipitation and solubilization of the elements. XRD spectrum revealed the precipitation of chromium carbides ( $\mathrm{Cr}_{23} C_{6}$ ) at $1068^{\circ} \mathrm{C}$ sintering temperature but its dissolution at $\mathrm{T} 1150 \mathrm{P} 60$ condition. Knowing that carbides enhance the hardness results, the decrease of the amount of $\mathrm{Cr}_{23} C_{6}$ with temperature may are responsible for the decrease on hardness from $292.00 \pm 0.00$ to $283.90 \pm 9.10 \mathrm{HV}$ when considering 60 $\mathrm{MPa}$ as pressure sintering [19].

This study presented higher hardness values than those found in literature regarding Inconel 718 specimens produced by other sintering technologies (Table 4).

Table 4

- Hardness values (HV -Vickers) of Inconel 718 specimens produced by several manufacturing techniques (B - Bottom; T -Top; V-Vertical).

\begin{tabular}{|lll|}
\hline Process & Hardness (HV) & REF \\
\hline This study & $292.0(100 \mathrm{~g} \mathrm{load})$ & - \\
\hline As-SLMed & B $(211.3) \mathrm{T}(204.9) \mathrm{V}(236.9)(50 \mathrm{~g} \mathrm{load})$ & [21] \\
\cline { 1 - 2 } As-SLMed + Homogenization & B $(289.1) \mathrm{T}(260.0) \mathrm{V}(282.6)(50 \mathrm{~g} \mathrm{load})$ & \\
\cline { 1 - 2 } As-SLMed + HIP & B (181.1) T (175.7) V (180.5) (50g load) & \\
\hline Laser Deposition & $275-350(300 \mathrm{~g})$ & [22] \\
\hline Field assisted hot pressing (FAHP) & $256.3(1000 \mathrm{~g})$ & [23] \\
\hline Microwave sintering & $191.2(1000 \mathrm{~g})$ & \\
\hline Metal injection Moudling & $211.3(1000 \mathrm{~g})$ & \\
\hline
\end{tabular}

Seede et al. [21] compared the microhardness in the bottom, top and vertical surface of the as-printed, homogenized $\left(1100^{\circ} \mathrm{C}\right.$ during 1 hour) and hot isostatic pressed $\left(1160^{\circ} \mathrm{C}\right.$ under $100 \mathrm{MPa}$ of pressure for 4 hours) SLMed specimens. Microhardness in the as fabricated (236.9 HV) is $19.3 \%$ lower than the homogenized specimens $(282.6 \mathrm{HV}$ ) due to more even distribution of secondary precipitates and the nucleation of smaller grains. In the opposite, the specimens with less amount of nucleation of smaller grains revealed lower hardness results (T1000P50 and T1000P60). However, these specimens also revealed poor densification with lack of diffusion and voids which lower the hardness results. The homogenized specimens presented the higher hardness results and closer to values to those obtained at this study $(292.0 \mathrm{HV})$. This was attributed to the large dispersion of $\gamma^{\prime \prime}\left(N_{3} N b\right)$ precipitates, revealing the presence of $100 \%$ of $\gamma(\mathrm{CrN} i)$ on XRD analysis. Parallelly, the specimens produced by Hot Pressing also revealed the $\gamma$ phase at a similar temperature $\left(1068^{\circ} \mathrm{C}\right)$ and hardening Chromium Carbides such as $\mathrm{NbC}$ and $\mathrm{Nb}_{4} \mathrm{C}_{3}$ originated by the large macrosegregation of $\mathrm{Nb}$ during solidification. On the other hand, 
the specimens subjected to HIP process showed a decrease on the hardness when compared with both as-SLMed and homogenized specimens. The high temperatures, pressure and time employed leaded to the high dissolution of $\gamma^{\prime \prime}$ phase leading to a significantly reduction of hardness results. Parallelly, Zhang et al [22] evaluated the microhardness of fibre laser deposited Inconel 718 using filler wire and also suggested that the dissolution of the principal strengthening phase $\gamma^{\prime \prime}$ during the laser cladding leaded to a lower hardness results than other heat treated and aged conditions.

Dugauguez et al [23] compared hardness results between three distinct processing techniques. These results should not be compared with the microhardness values due the influence of the indentation load/size effect (ISE) [24]. The specimens produced by FAHP presented higher hardness result (256.3 HV) than when compared with the remaining processes studied. The specimens produced by microwave sintering process revealed the lower hardness result $(191.2 \mathrm{HV})$ which was attributed to the presence of cracks on the surface due to the violent debinding and the occurrence of hot spots inside the specimen during sintering. The hardness of HIP treated specimens revealed proportional to the temperature because the increase in temperature enhances the solubilization and precipitation of the elements. In the present study, the low hardness results also were attributed of the presence of some defects such as voids (specimens produced at $1000^{\circ} \mathrm{C}$ ). The increase on hardness with temperature were also attributed the precipitation of some elements but also the increase on atomic diffusion and consequently powders consolidation.

\section{Conclusions And Future Perspectives}

This study allowed to conclude that densification of the Inconel 718 hot pressed specimen was enhanced by increasing the temperature sintering. The temperature has enhanced the atomic diffusion and so the powders bonding and consolidation. Regarding pressure conditions, the results did not reveal an evident influence on densification and hardness results.

- Inconel 718 specimens sintered at $1000^{\circ} \mathrm{C}$ revealed poor densification and hardness results which means that the temperature is not enough to promote the properly atomic diffusion and plastic deformation. The remaining sintering conditions presented densification levels between 97 and $100 \%$ and revealed a good inter-particle bonding because the fracture mode of the HPed specimens at this temperature was fully ductile dimple fracture.

- Regarding grain morphology, specimens produced at $1000^{\circ} \mathrm{C}$ revealed small grains scattered and mixed with large grains, indicating that they did not have the necessary temperature and time to grow. When increasing temperature to $1068^{\circ} \mathrm{C}$, a bi-modal random structure is presented with small and large grains. Most of the grains are grown but the total recrystallization is still not complete. Inconel 718 specimens produced at $1150^{\circ} \mathrm{C}$ showed a grown grain with a grain size homogeneity. there was not found grains that just nucleated.

- The lowest hardness values were at lower temperature $\left(1000^{\circ} \mathrm{C}\right)$ due to the poor bonding of compacted powders. The specimens produced at $1068^{\circ} \mathrm{C}$ and $1150^{\circ} \mathrm{C}$ sintering temperatures 
revealed similar hardness results. However, as the chromium carbides $\left(\mathrm{Cr}_{23} C_{6}\right)$ tended to decrease with the temperature, a slight hardness results decrease from 292 to $284 \mathrm{HV}$ were verified with the increasing of temperature.

- The optimization of Hot-pressing conditions of Inconel 718 alloy should consider a wide range of sintering pressure in order properly evaluate its influence on densification and mechanical properties.

\section{Declarations}

\section{Funding Resources}

This work was supported by FCT (Fundação para a Ciência e Tecnologia) through the grant national funds, under the national support to R\&D units grant, through the reference projects UIDB/04436/2020 and UIDP/04436/2020 and SFRH/BD/148031/2019] and the project Add: additive - add additive manufacturing to Portuguese industry [grant number POCI-01-0247-FEDER-024533].

\section{Conflicts of interest/Competing interest}

The authors declare that no known competing financial interests or personal relationships that could have appeared to influence the work reported in this paper.

\section{Availability or data and material}

All data used in this work have been properly cited within the article

\section{Code availability}

Not applicable.

\section{Ethics}

Not applicable.

\section{Consent to participate}

The authors declare that all authors have read and approved to submit this manuscript to IJAMT.

\section{Consent for publication}

The authors declare that all authors agree to sign the transfer of copyright for the publisher to publish this article upon on acceptance.

\section{Authors' contributions}

A. Marques: Methodology, Investigation, Writing - original draft, Visualization 
A. Cunha: Methodology, Writing - review \& editing, Investigation

F.S. Silva: Conceptualization, Supervision

F. Bartolomeu: Writing - review \& editing

O. Carvalho: Conceptualization, Writing - review \& editing, Supervision

\section{References}

1. Fecht $H$, Fecht $H$ (2000) Processing of nickel-base superalloys for turbine engine disc applications, in:Adv. Eng. Mater., : pp.777-787

2. Semiatin SL, McClary KE, Rollett AD, Roberts CG (2012) Microstructure evolution during supersolvus heat treatment of a powder metallurgy nickel-base superalloy, in: Artic. Source Type J. ISSN 10735623 DOI 10.1007/S11661-011-1035-y View More Metall.Mater. Trans. A Phys. Metall. Mater. Sci., : pp.1649-1661

3. R.R.I.. HPA, Dunstan Metal Injection Moulding of Heat Treated Alloy 718 Master Alloy, (n.d.)

4. Dowson G, Whittaker D (2008) Introduction to Powder Metallurgy The Process and Its Products, Eur. Powder Metall Assoc 36. https://doi.org/10.1017/CB09781107415324.004

5. Adrian P (2012) Mouritz, Introduction to Aerospace Materials,

6. Chang SH, Lee SC, Tang TP, Ho HH (2006) Evaluation of HIP pressure on Inconel 718 superalloy. Int J Cast Met Res 19:181-187. https://doi.org/10.1179/136404606225023408

7. Chang SH, Lee SC, Tang TP, Ho HH (2006) Effects of temperature of HIP process on characteristics of Inconel 718 superalloy. Int J Cast Met Res 19:175-180.

https://doi.org/10.1179/136404606225023399

8. Baccino R, Moret F, Pellerin F, Guichard D, Raisson G (2000) High performance and high complexity net shape parts for gas turbines: The ISOPREC $®$ powder metallurgy process. Mater Des 21:345-350. https://doi.org/10.1016/s0261-3069(99)00093-x

9. Chang L, Sun W, Cui Y, Yang R (2014) Influences of hot-isostatic-pressing temperature on microstructure, tensile properties and tensile fracture mode of Inconel 718 powder compact. Mater Sci Eng A 599:186-195. https://doi.org/10.1016/j.msea.2014.01.095

10. German RM, Pressure SWithE (2014) https://doi.org/10.1016/b978-0-12-401682-8.00010-0

11. Al A Nickel-Chromium Alloy Inconel Alloy 718 (UNS N07718),718(n.d.).

12. Manufacturing A, Additive $C$, Additive $C$, Powderrange CT, Steel S, Powderrange CT, Powder L, Fusion B, Powderrange CT (2019) TECHNICAL DATA SHEET CT PowderRange 316L F, Carpent. Addit Tech Data Sheets 1:1-4

13. Zieliñska M, Yavorska M, Porêba M, Sieniawski J (2010)Thermal properties of cast nickel based superalloys,

14. Metals S High-Performance Nickel Alloys - the Alloy Specialists., (n.d.). 
15. Easterling KE (1985) Hot-Isostatic Pressing Diagrams: New Developments 33:2163-2174

16. 718 alloy, Carpent. Technol. (n.d.). https://www.carpentertechnology.com/en/productsolutions/cartech-718-alloy/

17. Chaturvedi MC, Han Y (1983) Strengthening mechanisms in Inconel 718 superalloy. Met Sci 17:145149

18. Smialek, Meier (1987) High temperature oxidation in superalloy, Superalloy II.293-326

19. Peasura P, Poopat $B(2015)$ Investigation into the influence of post-weld heat treatment on the microstructure and hardness of inconel X-750. Adv Mech Eng 7:1-11.

https://doi.org/10.1177/1687814015578396

20. Sun W, Tan AWY, Wu K, Yin S, Yang X, Marinescu I, Liu E (2020) Post-process treatments on supersonic cold sprayed coatings: A review, Coatings. 10.

https://doi.org/10.3390/coatings10020123

21. Seede R, Mostafa A, Brailovski V, Jahazi M, Medraj M (2018) Microstructural and microhardness evolution from homogenization and hot isostatic pressing on selective laser melted inconel 718 : Structure, texture, and phases. J Manuf Mater Process 2. https://doi.org/10.3390/jmmp2020030

22. Kistler NA, Nassar AR, Reutzel EW, Corbin DJ, Beese AM (2017) Effect of directed energy deposition processing parameters on laser deposited Inconel ${ }^{\circledR} 718$ : Microstructure, fusion zone morphology, and hardness. J Laser Appl 29:022005. https://doi.org/10.2351/1.4979702

23. Dugauguez O, Torralba JM, Barriere T, Gelin JC (2016) Unconventional methods of sintering inconel 718 MIM Samples, Key Eng. Mater. 716 830-839.

https://doi.org/10.4028/www.scientific.net/KEM.716.830

24. Milman YV, Golubenko AA, Dub SN (2011) Indentation size effect in nanohardness. Acta Mater 59:7480-7487. https://doi.org/10.1016/j.actamat.2011.08.027

\section{Figures}




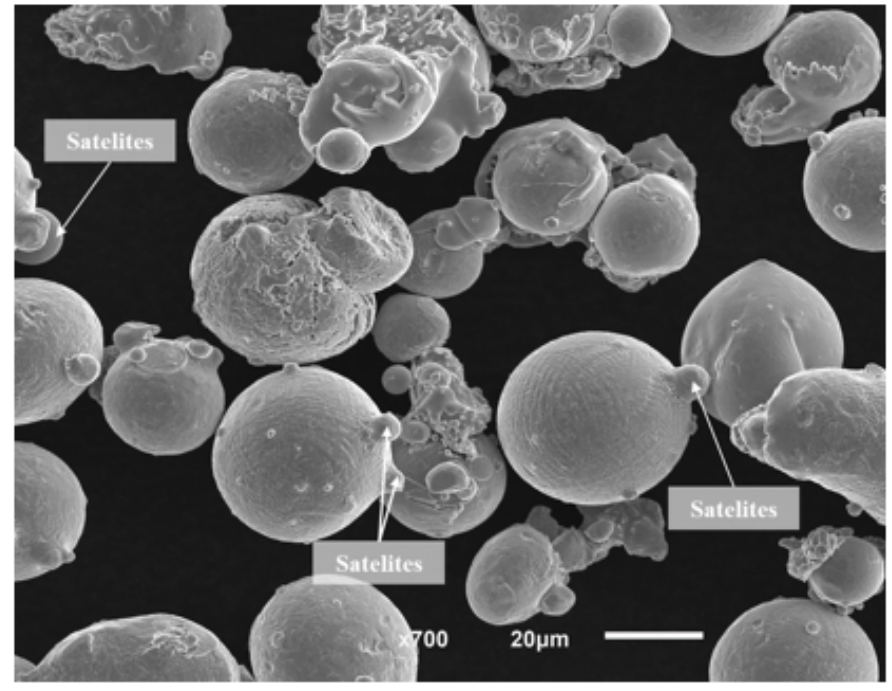

a)

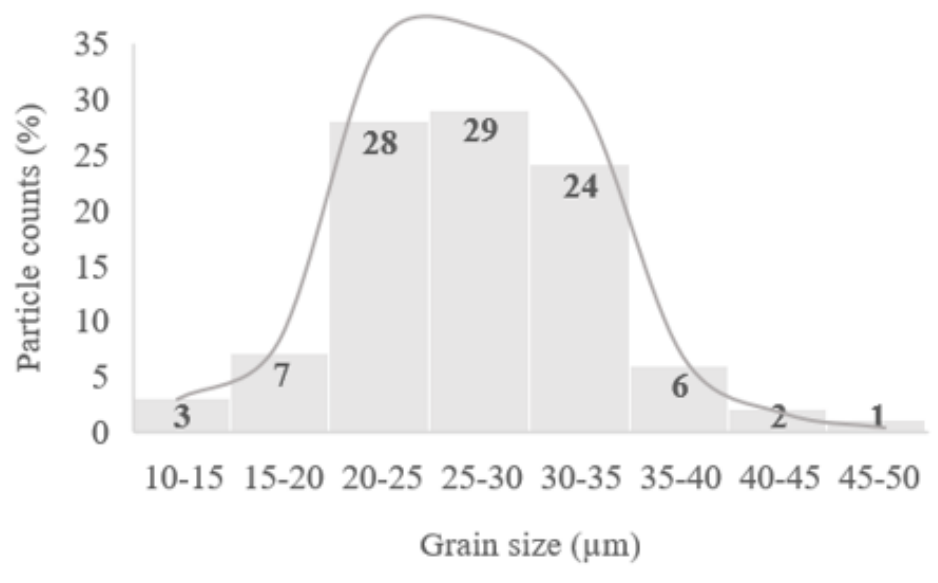

b)

\section{Figure 1}

a) SEM images of Inconel 718 alloy powders b) Particle size distribution of Inconel 718 powder.

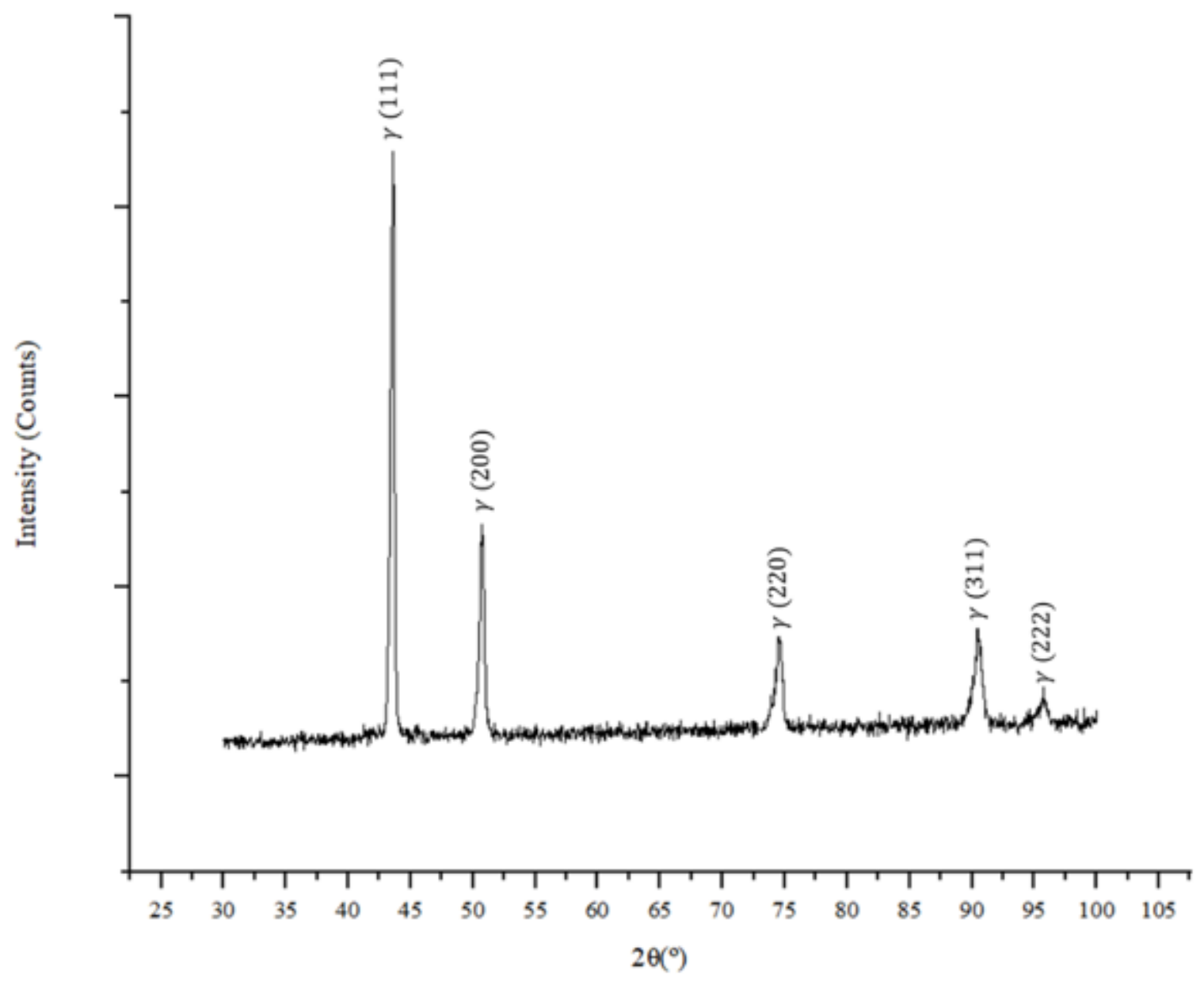

Figure 2 
XRD pattern of Inconel 718 powder.

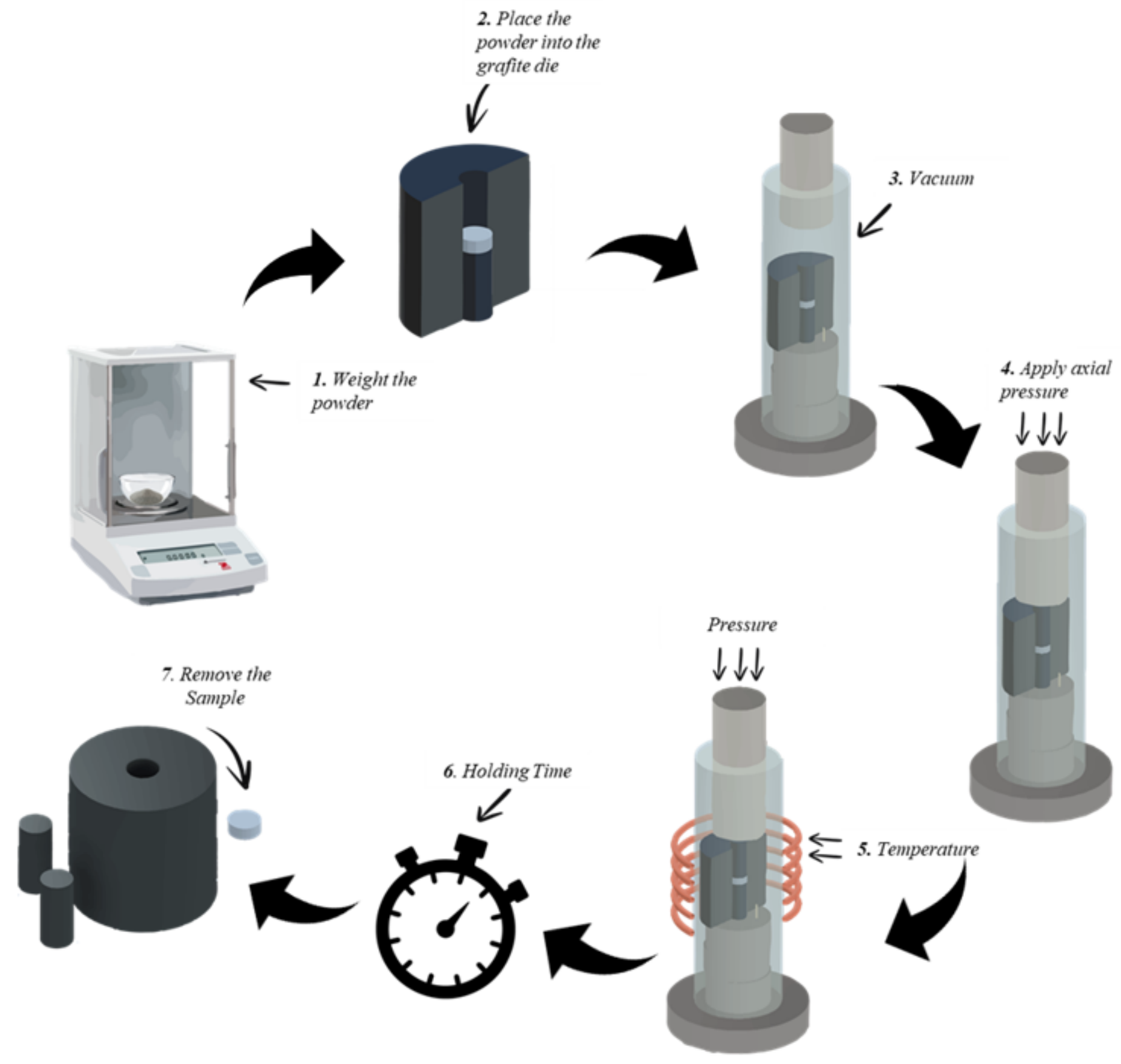

Figure 3

Schematic representation of the powder metallurgy technique - Hot Pressing. 

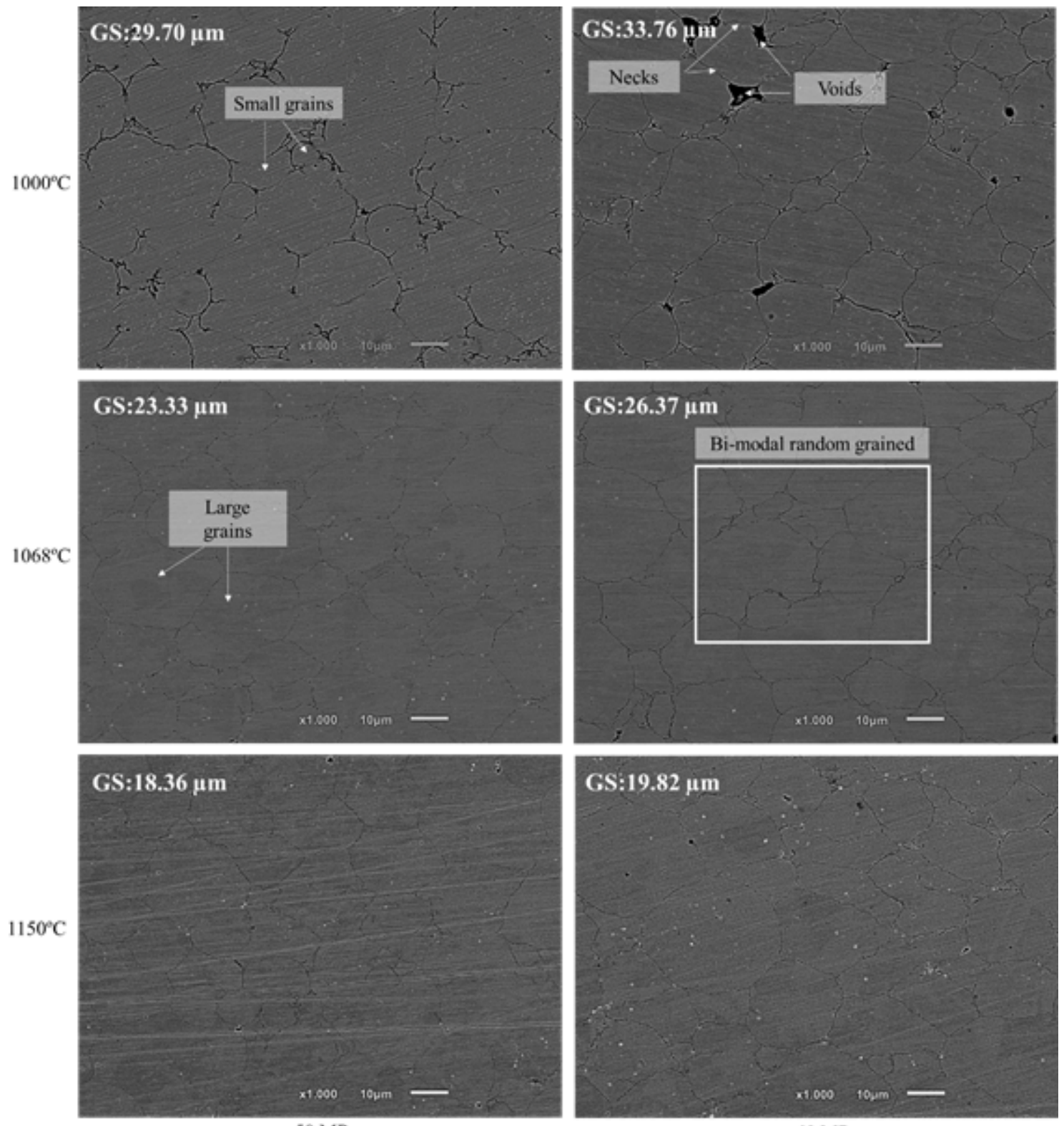

$50 \mathrm{MPa}$

$60 \mathrm{MPa}$

\section{Figure 4}

Grain morphology of Hot-pressed Inconel 718 specimens considering different sintering conditions. 


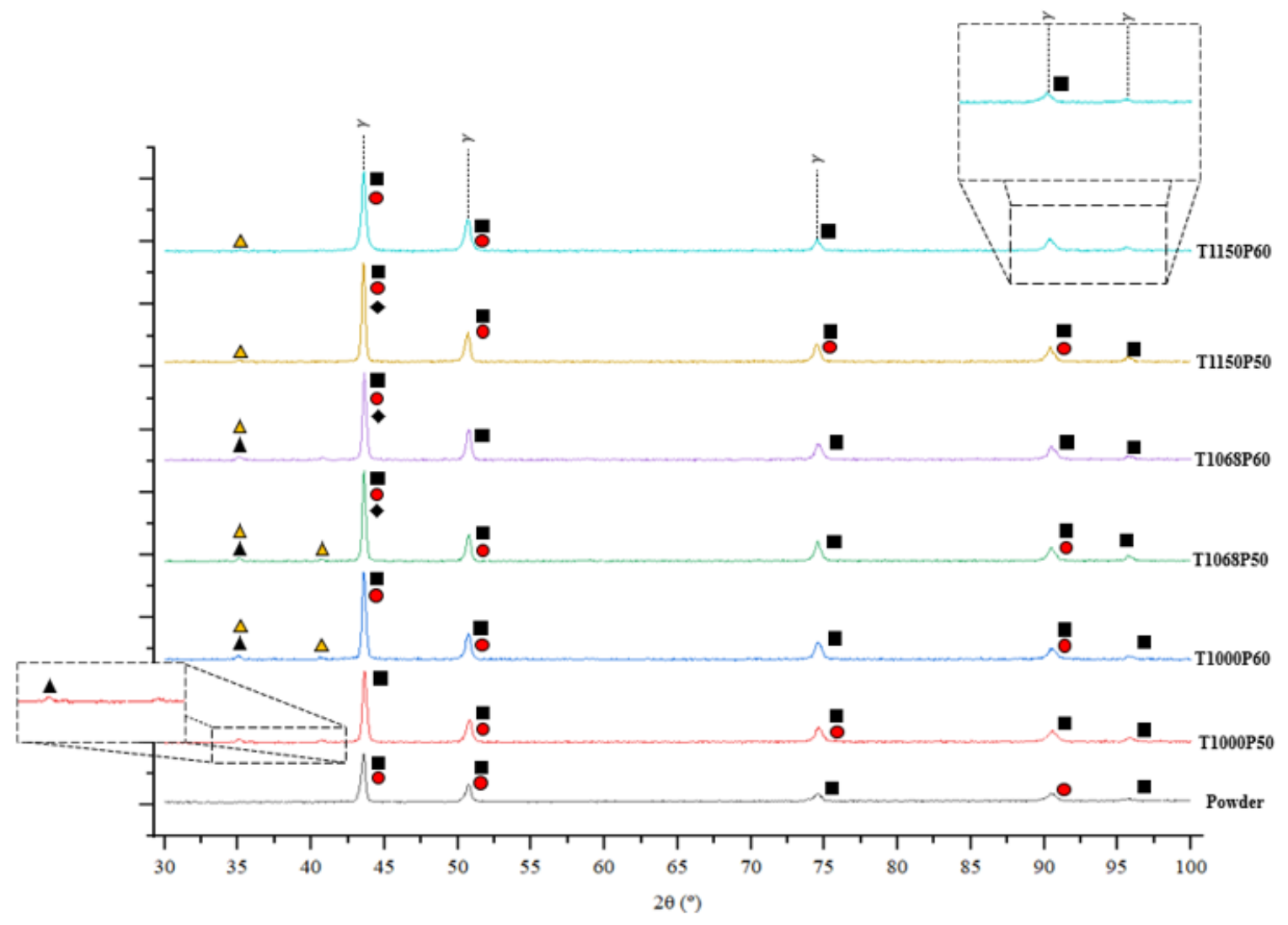

Figure 5

XRD patterns of Hot-Pressed Inconel 718 specimens. 

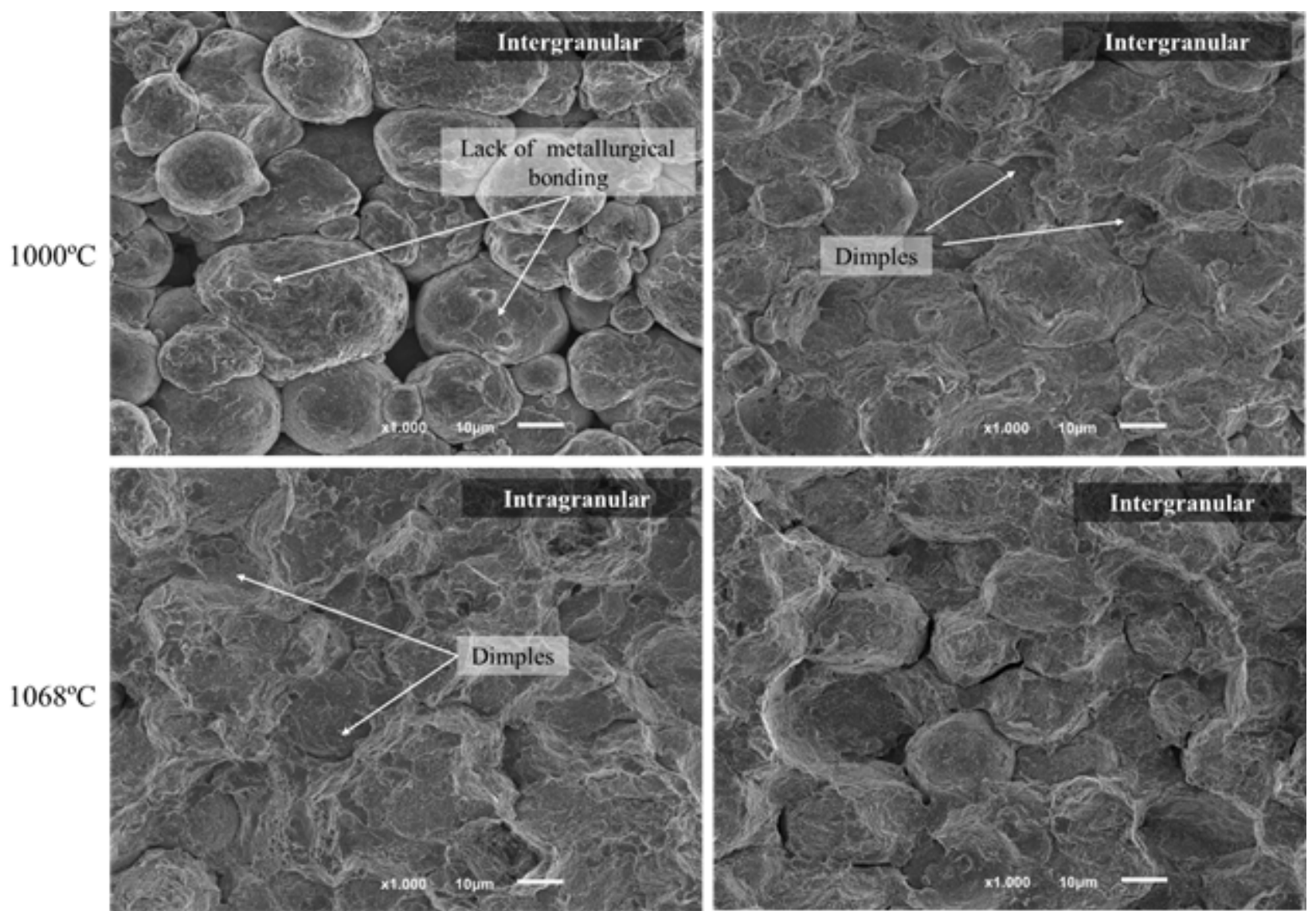

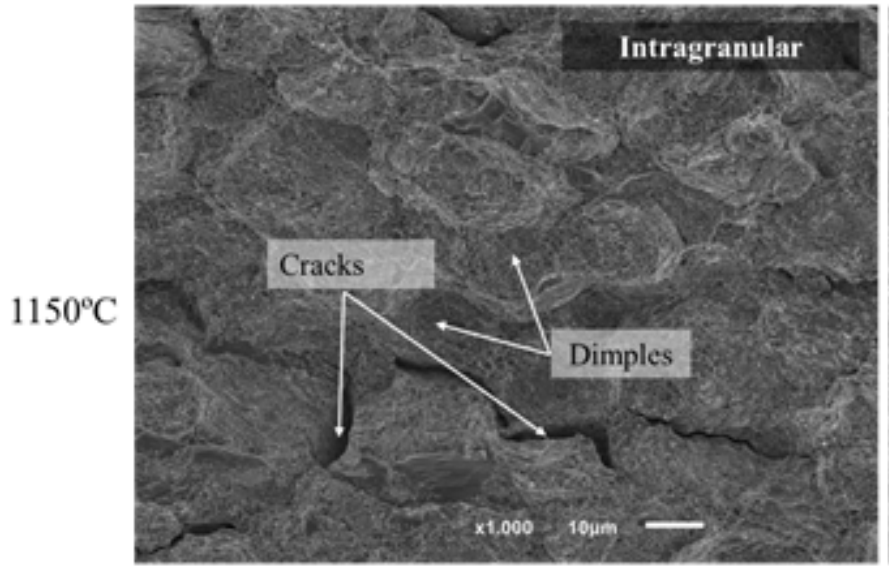

$50 \mathrm{MPa}$

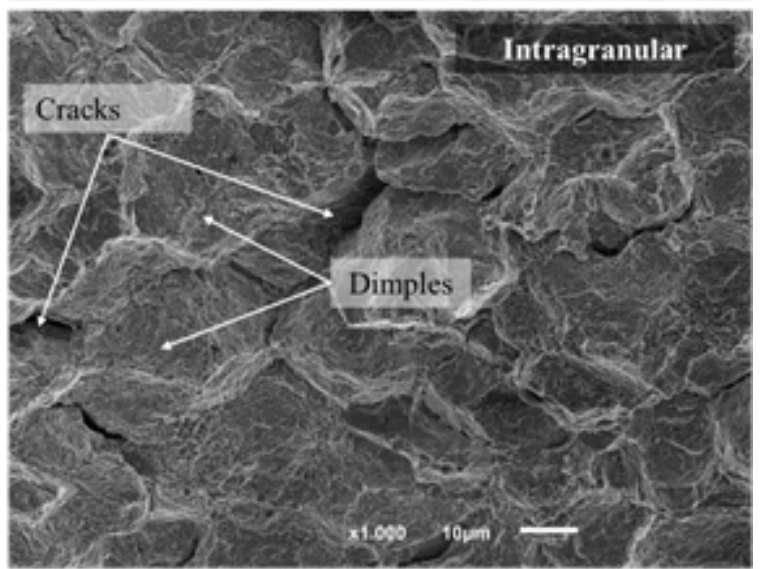

$60 \mathrm{MPa}$

\section{Figure 6}

Fracture surfaces of Hot-pressed Inconel 718 specimens at 1000, 1068 and $1150^{\circ} \mathrm{C}$ and 50 and $50 \mathrm{MPa}$. 


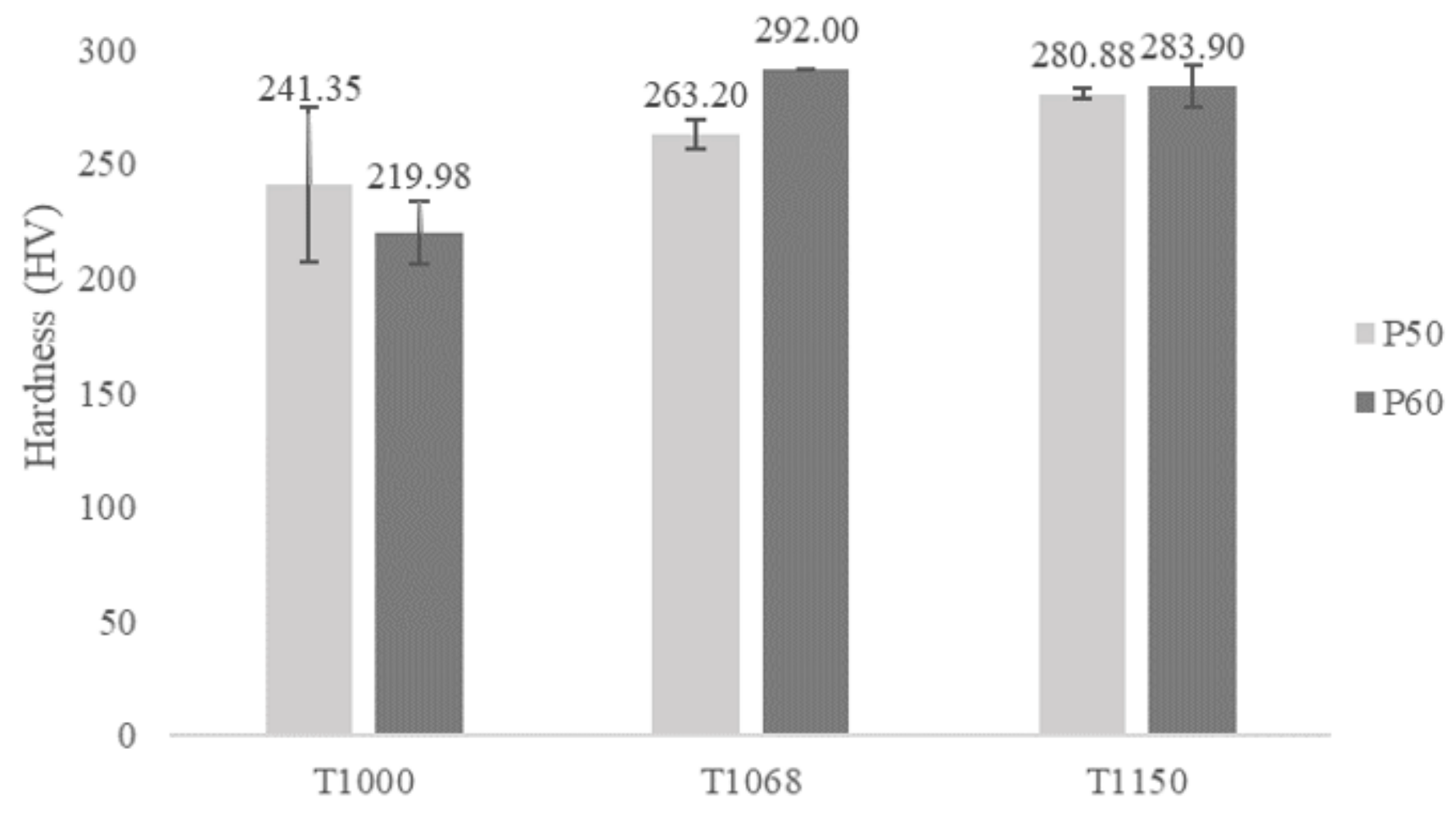

\section{Figure 7}

Hardness results of Inconel 718 specimens ( $\mathrm{T}$ - temperature in ${ }^{\circ} \mathrm{C}$ and $\mathrm{P}$ - pressure in $\mathrm{MPa}$ ). 